\title{
High-Conductivity Polymer Nanocomposites Obtained by Tailoring the Characteristics of Carbon Nanotube Fillers**
}

\author{
By Nadia Grossiord, Joachim Loos, Lucas van Laake, Maryse Maugey, Cécile Zakri, Cor E. Koning, and \\ A. John Hart*
}

We present a detailed study of the influence of carbon nanotube (CNT) characteristics on the electrical conductivity of polystyrene nanocomposites produced using a latex-based approach. We processed both industrially-produced multi-wall CNT (MWCNT) powders and MWCNTs from vertically-aligned films made in-house, and demonstrate that while the raw CNTs are individualized and dispersed comparably within the polymer matrix, the electrical conductivity of the final nanocomposites differs significantly due to the intrinsic characteristics of the CNTs. Owing to their longer length after dispersion, the percolation threshold observed using MWCNTs from vertically-aligned films is five times lower than the value for industrially-produced MWCNT powders. Further, owing to the high structural quality of the CNTs from vertically-aligned films, the resulting composite films exhibit electrical conductivity of $10^{3} \mathrm{~S} \mathrm{~m}^{-1}$ at $2 \mathrm{wt} \%$ CNTs. On the contrary, composites made using the industrially-produced CNTs exhibit conductivity of only tens of $\mathrm{S} \mathrm{m}^{-1}$. To our knowledge, the measured electrical conductivity for CNT/PS composites using CNTs from vertically-aligned films is by far the highest value yet reported for CNT/PS nanocomposites at this loading.

[*] Prof. A. J. Hart

Department of Mechanical Engineering, University of Michigan, 2278 GG Brown 2350 Hayward Street, Ann Arbor, MI $48109-2125$ (USA) E-mail: ajohnh@umich.edu

Dr. N. Grossiord, ${ }^{[+]}$Dr. J. Loos, Prof. C. E. Koning

Dutch Polymer Institute

P.O. Box 902, 5600 AX Eindhoven (The Netherlands)

Dr. N. Grossiord, Prof. C. E. Koning

Laboratory of Polymer Chemistry, Technical University of Eindhoven P.O. Box 513, 5600 MB Eindhoven (The Netherlands)

Dr. J. Loos

Laboratories of Polymer Technology and Materials and Interface Chemistry

Technical University of Eindhoven

P.O. Box 513, 5600 MB Eindhoven (The Netherlands)

L. C. van Laake $\mathrm{e}^{[++]}$

Department of Mechanical Engineering, Technical University of Eindhoven

P.O. Box 513, 5600 MB Eindhoven (The Netherlands)

M. Maugey, Dr. C. Zakri

Centre de Recherche Paul Pascal-CNRS

Avenue A. Schweitzer, 33600 Pessac (France)

[+] Present address: University of Warwick, Department of Chemistry, Coventry CV4 7AL, UK.

[++] Present address: Océ Technologies BV, PO Box 101, 5900 MA Venlo, The Netherlands.

[**] This work is part of the research program of the Dutch Polymer Institute (DPI), project \# 416. The work of John Hart was partially supported by a graduate fellowship from the Fannie and John Hertz Foundation. CNT growth was performed at MIT, where facilities were built and maintained using grants from the MIT Deshpande Center for Technological Innovation and the National Science Foundation (DMI \#052 1985), and lab space was provided by Prof. Yet-Ming Chiang and Prof. Brian Wardle. The authors are thank Hans Miltner (Free University of Brussels, Belgium) for performing the TGA measurements, as well as Prof. Philippe Poulin (Centre de Recherche Paul Pascal, CNRS, Pessac, France) for enlightening discussions regarding this research.

\section{Introduction}

The electrical conductivity of composites made of a conductive phase dispersed in an insulating matrix critically depends on the filler loading, as described by percolation theory. ${ }^{[1,2]}$ At a low filler concentration, the fillers are present as small clusters or individual elements; since the average distance between the filler elements exceeds their size, the conductivity of the nanocomposite is very close to that of the pure insulating matrix. When a sufficient amount of filler is loaded, a "percolation" path of connected fillers forms and allows charge transport through the sample. At this critical concentration, called the percolation threshold, the conductivity suddenly and rapidly increases. Based on geometrical considerations, the value of the percolation threshold is expected to be strongly influenced by the aspect ratio (ratio of length-to-diameter) of the filler particles. ${ }^{[3-6]}$ Considering a filler system having a particular filler orientation, the percolation threshold decreases with increasing aspect ratio of the filler. Carbon nanotubes (CNTs) are an attractive filler for making electrically conductive nanocomposites, since CNTs possess an excellent conductivity $\left(10^{5}-10^{8} \mathrm{~S} \mathrm{~m}^{-1[7,8]}\right)$, combined with a high aspect ratio (reaching 100-1000 for $\mu \mathrm{m}$ long single-wall and multi-wall CNTs). ${ }^{[9-12]}$ These composites are attractive for use in electromagnetic interference (EMI) shielding and electrostatic discharge (ESD) coatings, and as thin-film field-emitters and (at low CNT contents) transparent conductors. $^{[13-15]}$

Abundant literature on conductive CNT/polymer nanocomposites presents a striking variation in measured values of 
the percolation threshold, ranging from $0.0025 \mathrm{wt} \%^{[16]}$ to several wt\%. ${ }^{[12,17]}$ There is similar spread among the conductivity values, which often remain below $20 \mathrm{~S} \mathrm{~m}^{-1}$ (see references, ${ }^{[17-19]}$ among others). These disparities among published results can be explained by several factors. First, the structure and thus the resulting characteristics and properties of the CNTs depend on the production method, the post-production treatment, and, frequently, on the CNT batch even when the CNT manufacturing process parameters are not changed. Second, impurities such as amorphous carbon or catalyst particles, as well as defects (e.g., atomic vacancies, Stone-Wales rearrangements) result in lower electrical conductivity. ${ }^{[20-22]}$ Further, treatments such as purification and/or sonication can significantly damage the CNTs, causing defects and severing the CNTs. ${ }^{[23-25]}$ Third, when CNTs form a conductive network within a polymer matrix, the presence of an insulating polymer layer at each CNT-CNT junction prevents direct contact between the CNTs. ${ }^{[16,26-28]}$ As a result, the conductivity of the nanocomposite is much lower compared to a well-connected network of neat CNTs. To give an order of magnitude of this difference, the conductivities of CNT buckypapers (i.e., dense networks of pure CNTs without polymer) are typically $10^{4}-10^{5} \mathrm{~S} \mathrm{~m}^{-1[29-35]}$ whereas conductivities of CNT/polymer nanocomposites barely reach 10-100 S $\mathrm{m}^{-1}$ in the best cases. Last, as for any filler dispersed in an insulating matrix, the state of dispersion of the CNTs (notably the homogeneity, and the geometry and abundance of the CNT bundles ${ }^{[12,16,36,37]}$ ) as well as the type and the strength of fillermatrix interactions, ${ }^{[38]}$ are intimately affected by the nanocomposite production method; these factors substantially affect the electrical characteristics of the composite. In these respects, it is challenging to use the body of existing literature to evaluate the effect of the intrinsic properties of the CNTs, in particular their aspect ratio and their wall perfection, on the electrical conductivity of the CNT-polymer nanocomposites.

Further, a paramount issue in producing technologically relevant nanocomposites remains the ability to control the debundling of CNTs in polymer matrices, since the latter is directly correlated with the achievable conductivity and the mechanical properties of a given composite. ${ }^{[39-41]}$ As-produced CNTs mainly exist either in bundles and/or highly entangled ensembles. ${ }^{[42]}$ This characteristic remains a bottleneck for the use of CNTs as filler in a polymer matrix since CNTs tend to remain aggregated even after attempts are made to disperse them. Previously, we developed a latex-based concept to reproducibly make nanocomposites with well-dispersed CNTs by mixing an aqueous dispersion of mainly individual CNTs with polymer latex. In principle, any type of CNT may be used, after optimization of the exfoliation process. ${ }^{[43,44]}$ As a result, dispersing CNTs with specific characteristics into the same polymer matrix should help us to determine more precisely the real impact of the quality and/or aspect ratio values of the CNTs used on the conductivity behavior of the final nanocomposites.

Here, we present a detailed study of the influence of CNT length and quality on the electrical conductivity of polymer nanocomposites produced using the latex-based approach. We processed both industrially-produced MWCNT powders (denoted IPCNTs) and MWCNTs from vertically-aligned arrays (VGCNTs) made in-house, and demonstrate that while the raw CNTs are individualized and dispersed comparably within the polymer matrix, the conductivity of the final nanocomposites differs significantly due to the intrinsic characteristics of the CNTs. The percolation threshold observed using VGCNTs is five times lower than the value for industrially-produced MWCNT powders. Further, the resulting composite films have electrical conductivity of $10^{3} \mathrm{~S} \mathrm{~m}^{-1}$ at $2 \mathrm{wt} \% \mathrm{CNTs}$, which is to our knowledge, the highest conductivity value yet reported for CNT/PS nanocomposites at this loading.

\section{Results and Discussion}

\subsection{Characterization of As-Produced CNTs}

Figure 1 displays SEM images of the as-produced CNTs used in this study. The VGCNTs exhibit uniform alignment perpendicular to the $\mathrm{Si}$ substrate (Fig. 1b), whereas the IPCNTs are highly entangled and agglomerated (Fig. 1c). Figure 2 shows HRTEM images of typical samples of both types of MWCNTs. Two striking differences are apparent: the VGCNTs appear straight and have an average of 5-7 walls, corresponding to an average outer diameter of $9 \mathrm{~nm}$. On the contrary, the IPCNTs exhibit less structural order, and have an average diameter of $20 \mathrm{~nm}$, which corresponds to 15 walls as shown in the image. The batch VGCNT1 had a film height of $0.1 \mathrm{~mm}$, and VGCNT2 had a film height of $1.0 \mathrm{~mm}$; additional details are written in the experimental section.

\subsection{CNT Exfoliation}

By monitoring the exfoliation process with UV-Vis spectroscopy, it was observed that the VGCNTs required more energy to reach the maximum exfoliation than the IPCNTs (at least $40,000 \mathrm{~J}$ compared to $20,000 \mathrm{~J}$ ), as shown in Figure 3 . The maximum exfoliation denotes the point where additional sonication energy does not change the absorbance of the a)

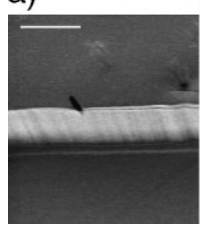

b)

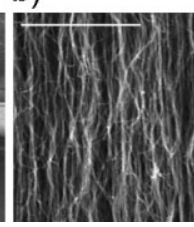

c)

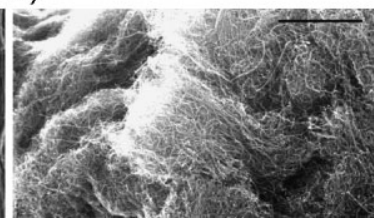

Figure 1. SEM images of an aligned MWCNT film (VGCNT2), for which the CNTs are still connected to the Si wafer on which they were grown: a) oblique view of the CNT film, where the lighter colored 'band' shows the CNTs which are located at the side of the CNT film, scale $250 \mu \mathrm{m}$; b) typical alignment of the CNTs of the film, viewed from the side, scale $1 \mu \mathrm{m}$; c) SEM image of the IPCNT powder, as-supplied, showing a highly entangled and agglomerated morphology, scale $1 \mu \mathrm{m}$. 
a)

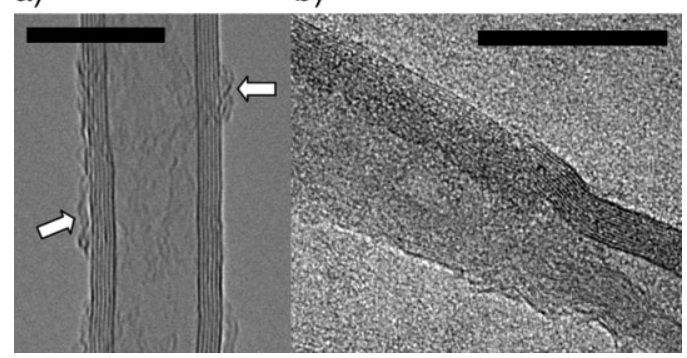

Figure 2. TEM images of CNTs used in this study: a) typically straight MWCNT from vertically-grown film (VGCNT2), having diameter $10 \mathrm{~nm}$; b) typical MWCNT from IPCNT agglomerate. The scale in (a) is $10 \mathrm{~nm}$ and the scale in (b) is $20 \mathrm{~nm}$. White arrows in (a) indicate amorphous carbon resident on the CNT sidewalls.

solution; identifying this process point is important in order to not induce excessive sonication damage to the CNTs. The additional energy required to exfoliate the VGCNTs is likely due to the attractive and steric interactions between the intertwined CNTs within the film. ${ }^{[45]}$ These interactions have been utilized to spin yarns of CNTs directly from VGCNT films. ${ }^{[46]}$ Differences of macroscopic grain sizes between VGCNT and IPCNT powders might also play a role since, despite the Ultra-Turrax ${ }^{\mathbb{R}}$ step, the VGCNT powder is less finely split at the beginning of the sonication than the IPCNT sample. The observed difference in the absorbance value at maximum exfoliation is caused by differences in the structure (i.e., diameter, length) and extinction coefficient between the IPCNTs and VGCNTs.

Sonication can cut $\mathrm{CNTs},{ }^{[10,11,47]}$ and consequently, the length of the as-produced CNTs is not necessarily equal to the length of the CNTs as-dispersed in the polymer matrix. As the percolation behavior of the nanocomposite is directly linked to the aspect ratio of the CNTs, the CNT length should be measured just after completion of the exfoliation process. The CNT length after exfoliation is expected to be equal to the

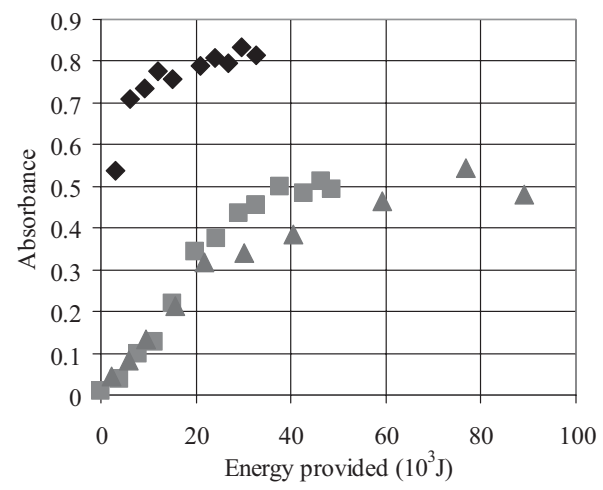

Figure 3. Evolution of the optical absorbance as a function of the total sonication energy provided to SDS-MWCNT dispersions of ( $\square$ ) VGCNT2s, (A) VGCNT1s, and (A) IPCNTs. Prior to the UV-Vis spectroscopy measurements, each sample was diluted, resulting in a CNT content of $3.33 \times 10^{-4} \mathrm{wt} \%$. Absorbance is reported at $265 \mathrm{~nm}$ for VGCNTs and $255 \mathrm{~nm}$ for IPCNTs. length of the CNTs dispersed in the final nanocomposites, since the freeze-drying and the mild low-shear processing steps are not expected to cut the CNTs.

The most straightforward way to determine the length of CNTs in dispersion is dynamic light scattering (DLS). ${ }^{[10,48]}$ Compared to microscopy techniques, DLS can use samples in solution, and provides an average measurement over a large number of CNTs. DLS was performed on the exfoliated SDSMWCNT dispersions. IPCNTs were found to be about (400 \pm 60$)$ $\mathrm{nm}$ long at the end of the exfoliation process, whereas the VGCNTs possessed an average length of $(1200 \pm 180) \mathrm{nm}$.

Kappes and coworkers ${ }^{[11,47]}$ demonstrated that the mechanism of sonication-induced scission of SWCNTs is similar to the mechanism of sonication-induced polymer chain scission. ${ }^{[49]}$ Due to forces of friction between the fluid (in our case water) and the macromolecule (either a CNT or a polymer chain, depending on the system considered), the macromolecule is under tension, and can break. According to Hennrich, ${ }^{[11]}$ the drag force $F_{\mathrm{M}}$ at the CNT center is proportional to the length of the CNT squared, meaning that long chains are correspondingly less resistant to cavitation-induced scission, in inverse square relation to their length. As a result, it is no surprise that the VGCNTs in solution after sonication are much shorter than there as-grown lengths. Further, the average lengths of the two batches of VGCNTs were of the same range at the end of the exfoliation, ca. $1 \mu \mathrm{m}$, regardless of the initial length of the asgrown CNTs. As the CNT length after sonication was the same for both batches (VGCNT1 and VGCNT2), further study was performed only with CNTs from batch VGCNT2.

\subsection{CNT Dispersion in the PS Matrix}

After exfoliation, the aqueous SDS-CNT dispersions were used to prepare conductive $\mathrm{CNT} /$ polymer nanocomposites. A scanning electron microscopy technique based on charge contrast imaging ${ }^{[50,51]}$ revealed the organization of the conductive CNT network, and confirmed that the dispersion of the CNTs in the polymer matrix was comparable for all the nanocomposites prepared. The SEM images of the surfaces of VGCNT2/PS and IPCNT/PS films possessing a CNT concentration above the percolation threshold (Fig. 4) show that both MWCNTs were well-dispersed and individualized in the polymer matrix. Besides many relatively straight CNTs, some are sharply bent yet appear continuous, exemplifying the flexibility of CNTs. ${ }^{[52]}$

\subsection{Electrical Conductivity of CNT/PS Nanocomposites}

Figure 5 shows the dependence of the electrical conductivity of the nanocomposites as a function of the CNT concentration, both for VGCNTs and IPCNTs dispersed in the PS matrix. At low CNT loading, when a conductive CNT network is not formed in the PS matrix, the conductivity of the composite remains very close to that of the pure insulating PS matrix. 

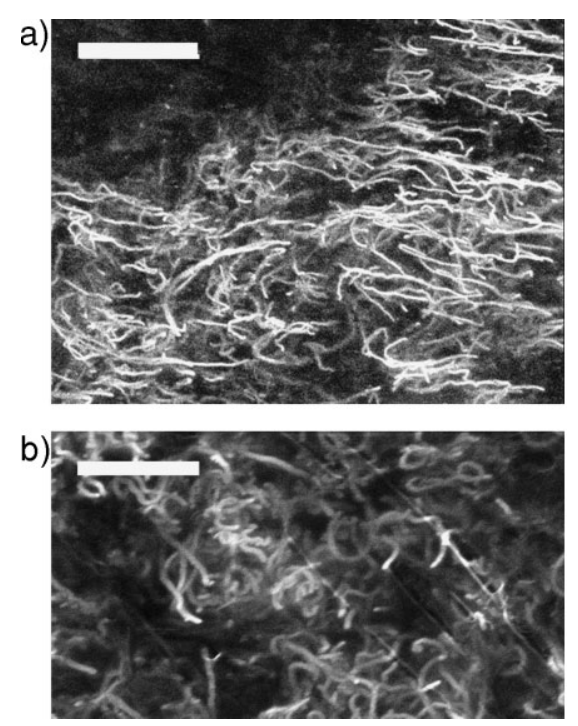

Figure 4. SEM images of the surface of CNT/PS nanocomposites, showing individualized CNTs: a) 1 wt\% VGCNT2; b) 2 wt\% IPCNTs. The scale in both photos is $1 \mu \mathrm{m}$.

When the so-called percolation threshold is reached, the filler particles form a conductive path throughout the matrix. At this critical concentration, i.e., $0.15-0.20 \mathrm{wt} \%$ VGCNT2s, the conductivity drastically increases by several orders of magnitude, from $10^{-10} \mathrm{~S} \mathrm{~m}^{-1}$ to $1 \mathrm{~S} \mathrm{~m}^{-1}$. At higher CNT loadings, e.g., between 1.5 and $2 \mathrm{wt} \%$, the conductivity stabilizes at around $10^{3} \mathrm{~S} \mathrm{~m}^{-1}$, which is, to the best of our knowledge, the highest value ever reported for MWCNT/PS nanocomposites at this low level of CNT loading. Comparable conductivity levels have been reported for CNT loadings far exceeding $10 \mathrm{wt} \%$ (see reference ${ }^{[53]}$ and articles cited therein). Figure 6 compares the conductivity of ${ }^{[54-63]}$ the VGCNT/PS composites

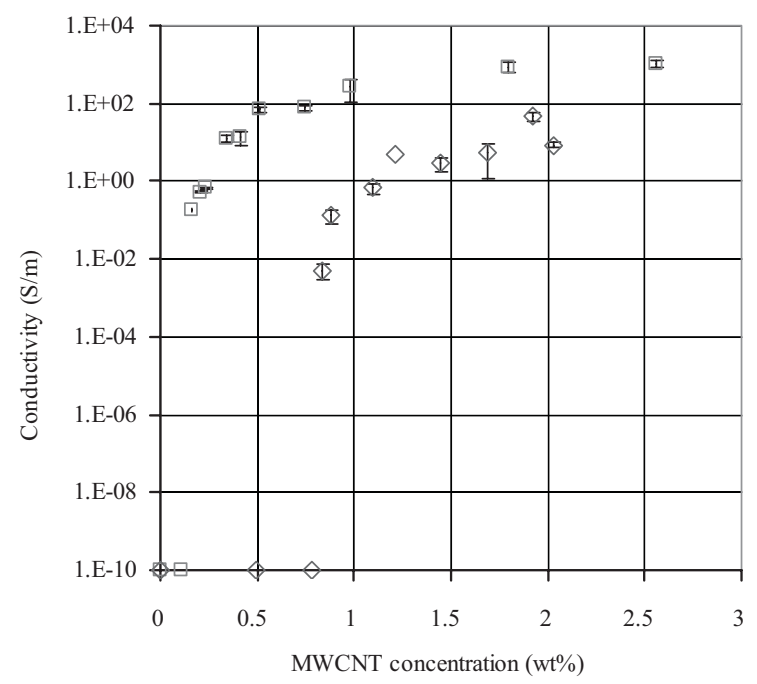

Figure 5. Four-point conductivity of MWCNT/PS composite as a function of MWCNT content: VGCNT2s ( $\square$; I IPCNTs $(-)$. Each point of the curve is the average of several measurements performed several times on several locations on both sides of the nanocomposite films.
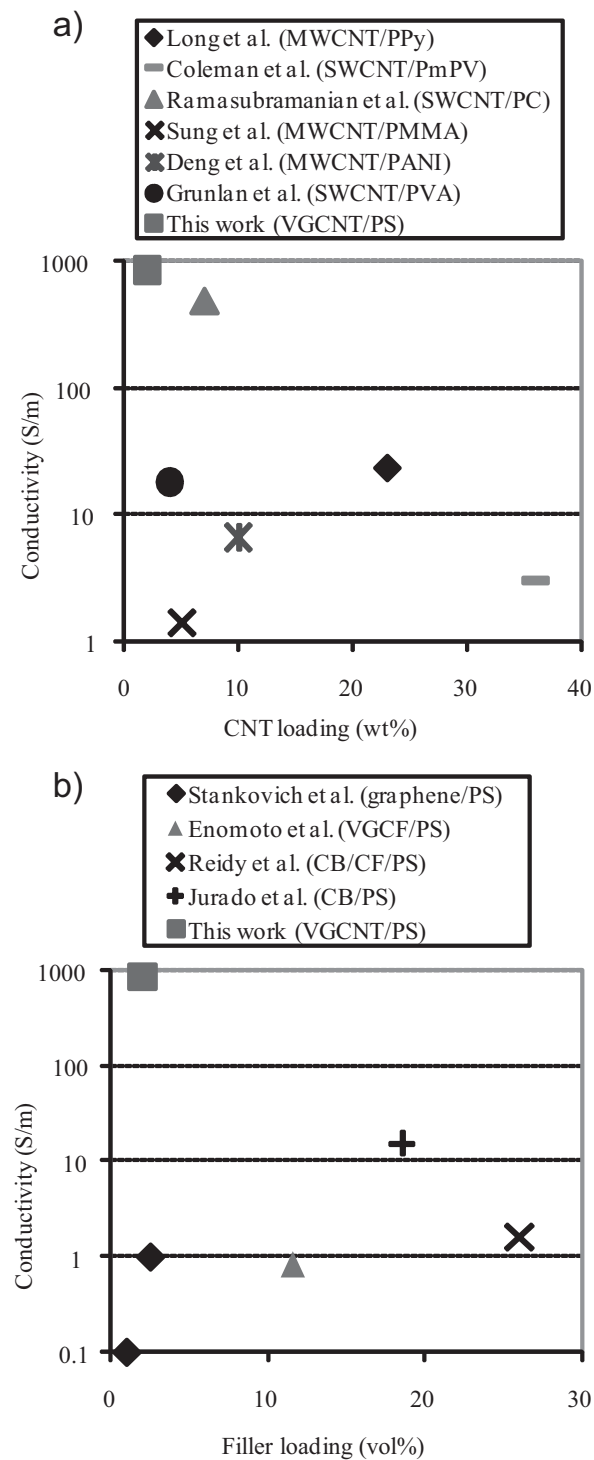

Figure 6. Comparison of present results to published electrical conductivity data [54-63] for polymer composites containing: a) CNT fillers; b) non-CNT carbon fillers including graphene sheets, vapor-grown carbon fibers (VGCF), carbon fibers (CF), and carbon black (CB).

made in the present study to published data of polymer composites made using CNTs and other carbon fillers. For the series of composites prepared with the IPCNTs, the percolation threshold is reached at about $0.85 \mathrm{wt} \%$ of CNTs, which is significantly higher than for the VGCNTs. The conductivity measured at about $1.8 \mathrm{wt} \%$ of IPCNT loading is only a few tens of $\mathrm{S} \mathrm{m}^{-1}$, which is far less than obtained for the VGCNT-based nanocomposites.

\subsection{On the Percolation Threshold of CNT/PS Nanocomposites}

The aspect ratio $(L / d)$ of the filler has a tremendous influence on the percolation threshold of the nanocomposite. 
According to several analytical models, the percolation threshold decreases in a hyperbolic fashion as a function of the aspect ratio of the filler. ${ }^{[3,4,64]}$ Simple models using continuum percolation and considering the filler network as a group of non-interacting sticks, suggest that the percolation threshold value (in volume fraction) scales as 1/a. This considers that the rod number density is roughly equal to the reciprocal of the excluded volume of the rods. ${ }^{[65-67]}$

Based on the latter models, the percolation threshold for VGCNT/PS is expected to be $0.0083 \mathrm{vol} \%$, considering an average length of $1200 \mathrm{~nm}$ and a diameter of $10 \mathrm{~nm}$ as measured by DLS and HRTEM. Considering the density of the MWCNTs, ${ }^{[68]}$ it follows that a value of $0.0083 \mathrm{vol} \%$ of VGCNTs corresponds to $0.0091 \mathrm{wt} \%$. This theoretical wt $\%$ is certainly higher for the IPCNTs because of their lower aspect ratios (roughly three times shorter CNTs at the end of the exfoliation, with a larger diameter of 10-30 nm), combined with a higher density (due to their higher number of walls compared to the VGCNTs). This confirms our experimental observation that the IPCNTs give a much higher percolation threshold than the VGCNTs.

However, the measured percolation threshold values are still one order of magnitude higher than the predicted values. Most percolation models assume that the fillers (notably CNTs) behave as non-interacting rigid rods. However, as shown in Figure 4, CNTs embedded in a polymer matrix are typically curved. Consequently, the theoretical percolation threshold calculated for straight sticks is an underestimate of the real value which is observed for curved and partly entangled rods. ${ }^{[52,69]}$ Matrix-particle and particle-particle interactions also likely influence the state of dispersion of the fillers in the matrix. Further, the presence of a thin polymer layer can prevent direct contact between $\mathrm{CNTs}^{[70,71]}$ ), and this can increase the effective percolation threshold by reducing the number of CNT-CNT contacts which are electrically conducting. ${ }^{[12,72-74]}$

Further, the lower observed percolation threshold for the VGCNTs is maintained despite the higher SDS/CNT ratio required to debundle VGCNTs. Because SDS has a lower dielectric constant than the PS matrix (about 1.5 and 2.5, respectively), ${ }^{[75,76]}$ it may lower the conductivity of the bulk polymer matrix. ${ }^{[77]}$ The CNT length polydispersity at the end of the sonication process was higher for the IPCNTs than for the VGCNTs, as determined by DLS. Kyrylyuk and van der Schoot ${ }^{[78]}$ showed that increasing the length polydispersity of the CNTs can significantly lower the percolation threshold.

\subsection{On the Maximum Conductivity of CNT/PS Nanocomposites}

The overall conductivity of a nanocomposite is governed by transport between adjacent filler particles, and transport through the conductive filler itself. Consequently, the difference of conductivity observed between the systems based on VGCNTs and IPCNTS is related to one of these parameters, if not to a combination of both.
Measurements performed on individual crossed CNTs at low bias voltage showed that the junction resistance between SWCNTs is at least several hundred $\mathrm{k} \Omega \cdot{ }^{[79]}$ Further, if there is a thin insulating polymer layer between the CNTs, the contribution of the filler-filler junction resistance is likely to be even larger than for a network of neat CNTs. Foygel et al. compared theoretical models to past experimental data and estimated that the CNT-CNT contact resistance within a polymer matrix can be as high as $10^{13} \Omega .^{[80]}$ Smaller-diameter CNTs have in principle a smaller CNT-CNT contact surface, and hence would have a higher junction resistivity, which results in a lower overall resistivity of the conduction network. ${ }^{[81]}$ Owing to the difference in this effect alone, we would expect the IPCNT/PS composite $(20 \mathrm{~nm}$ diameter) to have a higher conductivity than the VGCNT/PS composite, which is contrary to our measurements.

Turning to the effect of transport through the filler, we expect that the length and instrinsic structural characteristics of the CNTs will affect the conductivity of the nanocomposite measured above the percolation threshold. Assuming the electrical resistance of the filler is far less than the junction resistance, increasing the length of the filler should result in a net increase of the overall conductivity of the nanocomposite due to the reduction of the number of the total CNT-CNT junctions per length of conductive path. Theoretical simulations performed by Balberg ${ }^{[82]}$ showed that the conductivity of the network relates as a power law of the filler (stick) length as $\sigma \sim L^{2.48}$, for the limiting case when only contact resistivity determines the resistivity of the whole network. Accordingly, if we consider two polymer-filler systems, which are otherwise identical except filler F1 is three times the length of filler F2 (as in comparison of VGCNTs to IPCNTs), the resulting conductivity of the F1 system should be about 15 times that of the F2 system. This value is an upper limit for a hypothetical system where the influence of the contact resistivity at the junction is overestimated in comparison to a real system. However, this is very likely not the single factor to be taken into consideration, since the maximum conductivity of the VGCNT- and IPCNT-based systems differs by a factor 50-100, which is much greater than 15 .

Hecht et al. studied the conductivity of buckypapers made of CNTs of different lengths ${ }^{[81]}$ and concluded that the junction resistance largely dominates the overall resistivity of the CNT network, in comparison with the resistivity along the CNTs themselves. We made and characterized buckypapers using the SDS-stabilized CNTs and found that the VGCNT papers had 4-point conductivity $\approx 4000 \mathrm{~S} \mathrm{~m}^{-1}$ compared to $\approx 2000 \mathrm{~S} \mathrm{~m}^{-1}$ for IPCNT papers, with $\pm 35 \%$ experimental error. While this also points to higher intrinsic quality of the VGCNTs, we feel that the buckypaper measurements are less relevant to the present study because of the differences in preparation of buckypapers and composites, which likely lead to different network structures. Further, our buckypaper conductivities are substantially lower than other published results, ${ }^{[29,31,33,34]}$ likely due to the effect of SDS on the junction resistance. 
Additionally, different intrinsic conductivities of the CNTs may account for the different conductivities of the nanocomposites. Recently, Yan et al. modeled the conductivity of CNT/ polymer nanocomposites. ${ }^{[83]}$ They found that if the intrinsic conductivity of CNTs, dispersed in a polymer matrix increases from $3 \times 10^{4} \mathrm{~S} \mathrm{~m}^{-1}$ to $5.4 \times 10^{6} \mathrm{~S} \mathrm{~m}^{-1}$, the conductivity of the corresponding nanocomposites can increase by more than one order of magnitude. While it may have been instructive to measure the conductivities of individual IPCNTs and VGCNTs, challenges with isolating and contacting individual CNTs would make these measurements not fully instructive regarding electrical behavior of the composite network. Because there would be a distribution of CNT qualities, lengths, and diameters, we would need to measure a large number of CNTs, as well as ensure equivalent dispersion (degree of sonication-induced damage) conditions for both the individual CNT and composite tests.

Although we do not draw rigorous analysis using electrical measurements of individual CNTs or buckypapers, we can convincingly demonstrate that the VGCNTs have higher structural quality than the IPCNTs. First, TEM images (Fig. 2) suggest that the VGCNTs have significantly fewer structural defects than the IPCNTs; the VGCNT walls are relatively straight, whereas the IPCNT exhibits highly kinked and rippled graphitic layers. Therefore, we can expect that the intrinsic electrical conductivity of the VGCNTs is much higher, as structural defects can significantly affect the conductivity of CNTs, by inducing electron scattering. ${ }^{[22]}$

Second, we assess the structural quality of the CNTs by TGA. As shown in Figure 7 , the VGCNTs degrade at a temperature at least $150{ }^{\circ} \mathrm{C}$ higher than the IPCNTs. The maximum of the derivative of the thermogravimetry curve occurs at $711^{\circ} \mathrm{C}$ for the VGCNT2s, compared to $591^{\circ} \mathrm{C}$ for the IPCNTs. This difference occurs in spite of the higher curvature of the VGCNTs (due to their smaller diameter), which should lead to a slightly decreased thermal stability. ${ }^{[84]}$ Neither sample contains a significant quantity of catalyst particles since their residues at $800^{\circ} \mathrm{C}$, after burning, are approximately $2.5 \mathrm{wt} \%$ in all cases. A significant weight loss of $15 \%$ occurs around $175^{\circ} \mathrm{C}$ for the VGCNT2s. This weight loss is likely to be due to the degradation of amorphous carbon, ${ }^{[85-87]}$ which accumulates on the CNT walls due to gasphase pyrolysis of the hydrocarbon source.

Interestingly, TGA measurements performed on VGCNT1s did not show any significant weight loss at temperatures under $400{ }^{\circ} \mathrm{C}$. Thus, it appears that VGCNT1s had a lower content of amorphous carbon impurities than VGCNT2s. We expect that this occurs because amorphous carbon accumulates on the already-grown CNTs as film growth continues and gasphase reactants and products diffuse through the film, where the catalyst resides on the substrate. The VGCNT1 films are shorter, have spent less time in this environment, and accordingly contain less amorphous carbon. This also explains why it was more difficult to debundle VGCNT1s relative to VGCNT2s, as revealed by the higher required energy of sonication energy to reach maximum exfoliation (Fig.3).
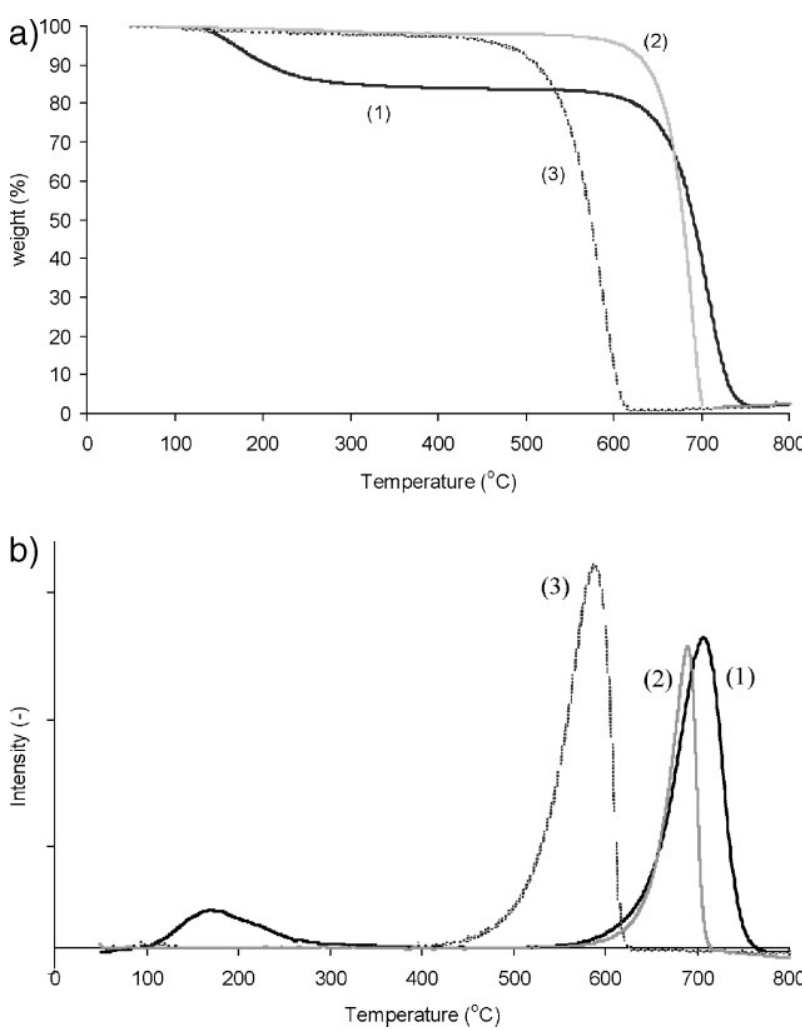

Figure 7. TGA measurements of (1) VGCNT2s, (2) VGCNT1s, and (3) IPCNTs performed under air at a flow rate of $25 \mathrm{sccm}$ and a heating rate of $5{ }^{\circ} \mathrm{C} \mathrm{min}^{-1}$ : a) weight versus temperature; b) derivative of weight versus temperature.

Absence (or removal by purification) of interstitial impurities between the CNTs can strengthen interactions between the CNTs by increasing the inter-CNT contact area. ${ }^{[88]}$ This can seriously hinder or even prevent the CNT individualization process. ${ }^{[43,89]}$ The IPCNTs do not show any weight loss below $400{ }^{\circ} \mathrm{C}$ because of a purification treatment applied by the manufacturer.

Finally, the higher degree of graphitization of the VGCNTS was further confirmed by Raman spectroscopy $(514.5 \mathrm{~nm}$, Kaiser Hololab 5000R) performed under the same conditions on the different types of CNTs used. Comparison of the normalized Raman spectra (not shown) indicate that the IPCNTs have a substantially lower $D / G$ intensity ratio than the VGCNTs. This implies that, comparatively, the VGCNTs have lower fractions of defective carbon than the IPCNTs, in spite of the additional amorphous carbon in the VGCNTs which is shown by TGA. However, as the intensity of the Raman spectrum of MWCNTs is typically low, it is difficult to make further quantitative comparisons using this technique.

\section{Conclusion}

Two series of MWCNT/PS nanocomposites were prepared, both by using the same latex-based technology, with two types 
of MWCNTs. Our goal was to study the influence of the characteristics of the CNTs on the overall conductivity of the final nanocomposites, without varying other important parameters like the type of polymer matrix used and the dispersion and aggregation state of the CNTs. This could be achieved because of the excellent reproducibility of the latex method. It was found that MWCNTs grown as vertically-aligned films, give MWCNT/PS nanocomposites with exceptional electrical properties, compared to nanocomposites prepared with 'standard' MWCNTs that are commercially available and grown as a powder. VGCNTs were found to possess higher structural quality than IPCNTs. In combination with relatively high aspect ratio values and small diameters, this leads to conductivity levels of the range of $10^{3} \mathrm{~S} \mathrm{~m}^{-1}$ for less than $2 \mathrm{wt} \%$ of MWCNT loading, which is, to the best of our knowledge, the highest conductivity yet reported for this MWCNT loading in CNT/polymer nanocomposites. Further, the percolation threshold of nanocomposites prepared with VGCNTs was measured to be about $0.15-0.2 \mathrm{wt} \%$, i.e., about 5 times lower than for IPCNT/PS systems. These results suggest that high-quality CNTs obtained from verticallyaligned films are a highly attractive filler material for making electrically-conductive polymer composites, for possible use in electrically-active coatings and thin-film electronic devices. Large-area production of vertically-aligned CNT films will be necessary to meet such a need; however, the similarities between substrate-bound and gas-phase CVD methods suggest that this method can be scaled efficiently at reasonable cost.

\section{Experimental}

Materials: Two types of MWCNTs were used in this study. First, we used vertically-aligned MWCNTs grown in-house, as detailed in the growth section. Second, we used a commercial MWCNT powder (Nanocyl-3100 batch 060213, Nanocyl SA). We denote the first type of CNTs as VGCNTs for "vertically-grown CNTs", and the second type as IPCNTs, for "industrially-produced CNTs".

CNT Growth: The vertically-aligned MWCNTs (named VGCNTs) were produced by thermal CVD as previously described by Hart and Slocum[90]. The growth substrate was a (100)-oriented silicon wafer (Silicon Quest International, USA), which was first coated with approximately $500 \mathrm{~nm}$ thermally-grown $\mathrm{SiO}_{2}$, and then coated with $1 / 10 \mathrm{~nm} \mathrm{Fe} / \mathrm{Al}_{2} \mathrm{O}_{3}$ by e-beam evaporation. CNT growth was performed in a single-zone atmospheric pressure quartz tube furnace (Lindberg), having an inside diameter of $22 \mathrm{~mm}$ and a $30 \mathrm{~cm}$ long heating zone, using flows of $\mathrm{He}$ (99.999\%, Airgas), $\mathrm{C}_{2} \mathrm{H}_{4}\left(99.5 \%\right.$, Airgas), and $\mathrm{H}_{2}$ ( $99.999 \%$, Airgas). The furnace temperature was ramped to the set point temperature in 15 minutes and held for an additional 10 minutes under 400/100 standard cubic centimeters per minute $(\mathrm{sccm}) \mathrm{H}_{2} / \mathrm{He}$. Then $100 \mathrm{sccm} \mathrm{C}_{2} \mathrm{H}_{4}$ was added for the growth period of $2 \mathrm{~min}$ for VGCNT1 and 15 min for VGCNT2. Finally, the $\mathrm{H}_{2}$ and $\mathrm{C}_{2} \mathrm{H}_{4}$ flows were discontinued and $600 \mathrm{sccm} \mathrm{He}$ was maintained for 10 more minutes to displace the reactant gases from the tube, before being reduced to a trickle while the furnace cools to below $150^{\circ} \mathrm{C}$. As characterized by TEM, the CNTs were typically multi-walled with an average outer diameter of $10 \mathrm{~nm}$. The height (thickness) of the films prepared in the first batch (VGCNT1) was approximately $100 \mu \mathrm{m}$, whereas the films prepared in the second batch (VGCNT2) were about $1 \mathrm{~mm}$ high.
CNT Exfoliation: All sonication processes, as well monitoring by UV-Vis spectroscopy, were carried out using the conditions described in[91]. For each type and batch of CNTs, the concentration of surfactant was chosen so as to individualize all of the CNTs which could be debundled by the sonication-driven debundling process (see method A in[92]). Exfoliation conditions for each batch of CNTs are as stated below.

IPCNTs: $0.2 \mathrm{wt} \%$ of IPCNTs was individualized in an aqueous $0.4 \mathrm{wt} \%$ SDS solution (SDS/CNT weight ratio of 2:1).

VGCNTs: Due to weak adhesion to the substrate, the VGCNT film was easily removed from the substrate using a razor blade, giving an almost catalyst-free, free-standing film. $0.04 \mathrm{wt} \%$ of CNTs was mixed with a $0.3 \mathrm{wt} \%$ aqueous SDS solution (SDS/CNT weight ratio of 7.5:1). This was first mixed using an Ultra-Turrax (IKA Works) at 24,000 rpm for 1 minute, followed by sonication under mild conditions $(20 \mathrm{~W}$, $20 \mathrm{kHz}$ ). Sonication was stopped when the maximum exfoliation of the CNTs was reached, as monitored by UV-Vis absorbance.[43,44,91] High shear mixing using the Ultra-Turrax allowed the CNT films to be finely split in the solution so that shorter sonication times were required to obtain a dispersion of maximally individualized CNTs[10].

Emulsion Polymerization: Emulsion polymerization was carried out in an oxygen-free atmosphere. $252 \mathrm{~g}$ styrene was mixed with $712 \mathrm{~g}$ water in the presence of $26 \mathrm{~g}$ sodium dodecyl sulfate (SDS) surfactant and $0.7 \mathrm{~g}$ sodium carbonate $\left(\mathrm{Na}_{2} \mathrm{CO}_{3}\right)$ buffer. The reaction was initiated by $0.7 \mathrm{~g}$ Sodium Persulfate (SPS) dissolved in $5 \mathrm{~g}$ of demineralized water. The polymerization was performed at a constant temperature of $50^{\circ} \mathrm{C}$. The polymer obtained (PS01) possessed mainly high molecular weight polymeric chains (peak molecular weight of about $1,000,000 \mathrm{~g} \mathrm{~mol}^{-1}$ ), with about $20 \mathrm{wt} \%$ of PS chains with a molecular weight lower than $20,000 \mathrm{~g} \mathrm{~mol}^{-1}$

Nanocomposite Preparation: The aqueous SDS-MWCNT dispersions obtained at the end of the exfoliation process were mixed at various concentrations with the PS latex (PS01) and freeze-dried (Chris Alpha 2-4). The resulting powder was degassed and transformed into films by compression molding (Collin Press 300G). Just before compression molding, the powder was heated for ten minutes until it reached $180^{\circ} \mathrm{C}$. Maintaining this temperature, heating was followed by a degassing step and two pressing steps at 40 bar for 20 seconds. The system was finally pressed at 100 bar for 2 minutes.

Microscopy: Samples for SEM imaging the dried CNT dispersions were prepared by first baking a Si wafer (Topsil Inc., Denmark) at $750^{\circ} \mathrm{C}$ in air for 24 hours. After plasma cleaning (Emitech K1050X), the wafer was sealed with two millilitres of 3-aminopropyl-trimethoxy silane in Ar environment. The treated wafer was heated for one hour at $80{ }^{\circ} \mathrm{C}$ to allow the chemicals to react at the surface of the Si wafer in order to create amine groups, which facilitate binding of the CNTs to the wafer surface. Finally, the Si wafer was washed with methanol in order to remove any unreacted 3-aminopropyl-trimethoxy silane. SEM images were taken using a Philips/FEI XL30 ESEM-FEGF equipped with a field emission electron source. The surfaces of the nanocomposites were imaged by SEM under the conditions described in reference [50]. High resolution TEM of the individual CNTs was performed by using either a JEOL-2011 or a Tecnai 20 (FEI Co., The Netherlands), both operated at $200 \mathrm{keV}$. The samples were prepared by dipping a copper TEM grid in the MWCNT dispersions, followed by subsequent drying.

Thermogravimetry: Thermogravimetry (TGA) experiments were performed on a TA Instrument Q5000 TGA under dry air flow $(25 \mathrm{~mL}$ $\mathrm{min}^{-1}$ ). Typically, $1 \mathrm{mg}$ of product was placed in a platinum crucible and heated from room temperature up to $900^{\circ} \mathrm{C}$ at a rate of $5^{\circ} \mathrm{C} \mathrm{min}{ }^{-1}$.

Dynamic Light Scattering: Dynamic light scattering measurements were performed under conditions described by Badaire et al.[10]; the only difference is that a laser wavelength of $532 \mathrm{~nm}$ was used in the present study.

Electrical Resistivity: Two-point and four-point electrical conductivity measurements were performed using a Keithley 6512 Programmable Electrometer, which was used either alone or in combination with a Keithley 220 Programmable Current Source. Measurements 
were performed directly on the surface of the films. The contact between the sample and the measuring probe was improved using a colloidal graphite paste (Electron Microscopy Sciences, 12660) [93,94].

Received: April 18, 2008

[1] S. Kirkpatrick, Rev. Mod. Phys. 1973, 45(4), 574.

[2] D. Stauffer, A. Aharony, Introduction to Percolation Theory, Taylor and Francis, London 1992.

[3] A. Celzard, E. McRae, C. Deleuze, M. Dufort, G. Furdin, J. F. Marêché, Phys. Rev. B 1996, 53, 6209.

[4] S. H. Munson-McGee, Phys. Rev. B 1991, 43, 3331.

[5] D. M. Bigg, D. E. Stutz, Polym. Compos. 1983, 4, 40

[6] J. Y. Yi, G. M. Choi, J. Electroceram. 1999, 3, 361.

[7] A. Y. Kasumov, I. I. Khodos, P. M. Ajayan, C. Colliex, Europhys. Lett. 1996, 34,429

[8] P. L. McEuen, M. S. Fuhrer, H. Park, IEEE Trans. Nanotech. 2002, 1, 78

[9] M. S. Dresselhaus, G. Dresselhaus, P. C. Eklund, Science of Fullerenes and Carbon Nanotubes, Academic, London 1996.

[10] S. Badaire, P. Poulin, M. Maugey, C. Zakri, Langmuir 2004, 20, 10367.

[11] F. Hennrich, R. Krupke, K. Arnold, J. A. Rojas Stütz, S. Lebedkin, T. Koch, T. Schimmel, M. M. Kappes, J. Phys. Chem. B 2007, 111, 1932.

[12] M. B. Bryning, M. F. Islam, J. M. Kikkawa, A. C. Yodth, Adv. Mater. 2005, 17, 1186.

[13] M. Endo, T. Hayashi, Y. A. Kim, M. Terrones, M. S. Dresselhaus, Philos. Trans. R. Soc. London Ser. 2004, 362, 2223.

[14] R. H. Baughman, A. A. Zakhidov, W. A. de Heer, Science 2002, 297, 787.

[15] W. S. Kim, H. S. Song, B. O. Lee, K. H. Kwon, Y. S. Lim, M. S. Kim, Macromol. Res. 2002, 10, 253.

[16] J. K. W. Sandler, J. E. Kirk, M. S. P. Shaffer, A. H. Windle, Polymer 2003, 44, 5893.

[17] N. Grossiord, J.Loos, O.Regev, C. E. Koning, Chem. Mater. 2006, 18, 1089.

[18] K. I. Winey, T. Kashiwagi, M. Mu, MRS Bull. 2007, 32, 348.

[19] D. T. Colbert, Plast. Add. Comp. 2003, 5, 18.

[20] H. Dai, E. W. Wong, C. M. Lieber, Science 1996, 272, 523.

[21] H. Stahl, J. Appenzeller, R. Martel, P. Avouris, B. Lengeler, Phys. Rev. Lett. 2000, 85, 5186

[22] C. Gómez-Navarro, P. J. de Pablo, J. Gómez-Herrero, B. Biel, F. J. Garcia-Vidal, A. Rubio, F. Flores, Nat. Mater. 2005, 4, 534

[23] J. Liu, A. G. Rinzler, H. Dai, J. H. Hafner, R. K. Bradley, P. J. Boul, A. Lu, T. Iverson, K. Shelimov, C. B. Huffman, F. Rodriguez-Macias, Y.S. Shon, T. R. Lee, D. T. Colbert, R. E. Smalley, Science 1998, 280 , 1253.

[24] K. L. Lu, M. R. Lago, Y. K. Chen, M. L. H. Green, P. J. F. Harris, S. C. Tsang, Carbon 1996, 34, 814.

[25] M. Monthioux, B. W. Smith, B. Burteaux, E. Claye, J. E. Fischer, D. E. Luzzi, Carbon 2001, 39, 1251

[26] J.-M. Benoit, B. Corraze, S. Lefrant, W. J. Blau, P. Bernier, O. Chauvet, Synth. Met. 2001, 121, 1215.

[27] B. E. Kilbride, J. N. Coleman, J. Fraysse, P. Fournet, M. Cadek, A. Drury, S. Hutzler, S. Roth, W. J. Blau, J. Appl. Phys. 2002, 92, 4024

[28] E. Kymakis, G. A. J. Amaratunga, J. Appl. Phys. 2006, 99, 084302.
[29] U. Dettlaff-Weglikowska, V. Skákslová, R. Graupner, S. H. Jhang, B. H. Kim, H. J. Lee, Y. W. Park, S. Berber, D. Tománek, S. Roth, J. Am. Chem. Soc. 2005, 127, 5125.

[30] M. Kaempgen, G. S. Duesberg, S. Roth, Appl. Surf. Sci. 2005, 252, 425.

[31] E. Bekyarova, M. E. Itkis, N. Cabrera, B. Zhao, A. Yu, J. Gao, R. C. Haddon, J. Am. Chem. Soc. 2005, 127, 5990.

[32] Z. Wu, Z. Chen, X. Du, J. M. Logan, J. Sippel, M. Nikolou, K. Kamaras, J. R. Reynolds, D. B. Tanner, A. F. Hebard, A. G. Rinzler, Science 2004, 305, 1273.

[33] Y. Zhou, L. Hu, G. Grüner, Appl. Phys. Lett. 2006, 88, 123109.

[34] D. Zhang, K. Ryu, X. Liu, E. Polikarpov, J. Ly, M. E. Tompson, C. Zhou, Nano Lett. 2006, 6, 1880.

[35] J. Li, L. Hu, L. Wang, Y. Zhou, G. Grüner, Y. J. Marks, Nano Lett. 2006, 6, 2472

[36] J. Sandler, M. S. P. Shaffer, T. Prasse, W. Bauhofer, K. Schulte, A. H Windle, Polymer 1999, 40, 5967.

[37] R. Schueler, J. Petermann, K. Schulte, H.-P. Wentzel, J. Appl. Polym Sci. 1997, 63, 1741.

[38] K. Miyasaka, K. Watanabe, E. Jojima, H. Aida, M. Sumita, K Ishikawa, J. Mater. Sci. 1982, 17, 1610.

[39] R. H. Baughman, A. A. Zakhidov, W. A. de Heer, Science 2002, 297, 787.

[40] R. H. Schmidt, I. A. Kinloch, A. N. Burgess, A. H. Windle, Langmuir 2007, 23, 5707.

[41] X. Gong, J. Liu, S. Baskaran, R. D. Voise, J. S. Young, Chem. Mater 2000, 12, 1049.

[42] A. Thess, R. Lee, P. Nikolaev, H. Dai, P. Petit, J. Robert, C. Xu, Y. H Lee, S. G. Kim, A. G. Rinzler, D. T. Colbert, G. E. Scuseria, D. Tomanek, J. E. Fischer, R. E. Smalley, Science 1996, 273, 483.

[43] N. Grossiord, O. Regev, J. Loos, J. Meuldijk, C. E. Koning, Anal. Chem. 2005, 77, 5135

[44] J. Yu, N. Grossiord, C. E. Koning, J. Loos, Carbon 2007, 45, 618.

[45] P. van der Schoot, T. Odijk, J. Chem. Phys. 1992, 97, 515.

[46] M. Zhang, K. R. Atkinson, R. H. Baughman, Science 2004, 306, 1358

[47] K. Arnold, F. Hennrich, R. Krupke, S. Lebedkin, M. M. Kappes, Phys. Status Solidi B 2006, 243, 3073

[48] C. Branca, V. Magazù, A. Mangione, Diamond Relat. Mater. 2005, 14 , 846.

[49] M. W. A. Kuijpers, P. D. Iedema, M. F. Kemmere, J. T. F. Keurentjes, Polymer 2004, 45, 6461.

[50] J. Loos, A. Alexeev, N. Grossiord, C. E. Koning, O. Regev, Ultramicroscopy 2005, 104, 160.

[51] J. Z. Kovacs, K. Andresen, J. R. Pauls, C. P. Garcia, M. Schossig, K. Schulte, W. Bauhofer, Carbon 2007, 45, 1279.

[52] F. Dalmas, R. Dendievel, L. Chazeau, J.-Y. Cavaillé, C. Gauthier, Acta Mater. 2006, 54, 2923.

[53] F. M. Blighe, Y. R. Hernandez, W. J. Blau, J. N. Coleman, Adv. Mater 2007, 19, 4443.

[54] J. G. Deng, X. B. Ding, W. C. Zhang, Y. X. Peng, J. H. Wang, X. P. Long, P. Li, A. S. C. Chan, Eur. Polym. J. 2002, 38, 2497.

[55] R. Ramasubramaniam, J. Chen, H. Liu, Appl. Phys. Lett. 2003, 83 , 2928.

[56] Y. Z. Long, Z. J. Chen, X. T. Zhang, J. Zhang, Z. F. Liu, J. Phys. D 2004, 37, 1965.

[57] J. N. Coleman, S. Curran, A. B. Dalton, A. P. Davey, B. McCarthy, W. Blau, R. C. Barklie, Phys. Rev. B 1998, 58, R7492.

[58] J. H. Sung, H. S. Kim, H. J. Jin, H. J. Choi, I. J. Chin, Macromolecules 2004, 37, 9899.

[59] J. C. Grunlan, A. R. Mehrabi, M. V. Bannon, J. L. Bahr, Adv. Mater 2004, 16, 150.

[60] S. Stankovich, D. A. Dikin, G. H. B. Dommett, K. M. Kohlhaas, E. J. Zimney, E. A. Stach, R. D. Piner, S. T. Nguyen, R. S. Ruoff, Nature 2006, 442, 282. 
[61] K. Enomoto, T. Yasuhara, N. Ohtake, K. Kato, JSME Int. J. A: Solid Mech. Mater. Eng. 2003, 46, 353.

[62] R. F. Reidy, G. Simkovich, J. Mater. Sci. 1993, 28, 799.

[63] J. R. Jurado, C. Moure, P. Duran, M. Rodriguez, A. Lìnares, J. L. Acosta, J. Mater. Sci. 1991, 26, 4022.

[64] N. Ueda, M. Taya, J. Appl. Phys. 1986, 60, 459.

[65] I. Balberg, C. H. Anderson, S. Alexander, N. Wagner, Phys. Rev. B 1984, 30, 3933.

[66] F. Carmona, P. Delhaes, F. Barreau, D. Ordiera, R. Canet, L. Lafeychine, Rev. Chim. Miner. 1981, 18, 498.

[67] A. L. R. Bug, S. A. Safran, I. Webman, Phys. Rev. Lett. 1985, 54, 1412.

[68] E. T. Thostenson, T.-W. Chou, J. Phys. D 2003, 36, 573.

[69] C. Li, E. T. Thostenson, T.-W. Chou, Compos. Sci. Technol., in press.

[70] W. Y. Hsu, W. G. Holtje, J. R. Barkley, J. Mater. Sci. Lett. 1988, 7, 459.

[71] I. Balberg, D. Azulay, D. Toker, O. Millo, Int. J. Mod. Phys. B 2004, 18, 2091.

[72] A. L. R. Bug, S. A. Safran, G. S. Grest, I. Webman, Phys. Rev. Lett. 1985, $55,1896$.

[73] B. Vigolo, C. Coulon, M. Maugey, C. Zakri, P. Poulin, Science 2005, 309, 920.

[74] A. V. Kyrylyuk, P. Van der Schoot, unpublished.

[75] S. M. Bachilo, M. S. Strano, C. Kittrell, R. H. Hauge, R. E. Smalley, R. B. Weisman, Science 2002, 298, 2361.

[76] G. Birnbaum, J. Franeau, J. Appl. Phys. 1949, 20, 817.

[77] A. B. Kaiser, Rep. Prog. Phys. 2001, 64, 1.

[78] A. V. Kyrylyuk, P. Van der Schoot, Proc. Natl. Acad. Sci. USA, in press.

[79] M. S. Fuhrer, J. Nygård, L. Shih, M. Forero, Y.-G. Yoon, M. S. C. Mazzoni, H. J. Choi, J. Ihm, S. G. Louie, A. Zettl, P. L. McEuen, Science 2000, 288, 494
[80] M. Foygel, R. D. Morris, D. Anez, S. French, V. L. Sobolev, Phys. Rev. B 2005, 71, 104201.

[81] D. Hecht, L. Hu, G. Grüner, Appl. Phys. Lett. 2006, 89, 133112.

[82] I. Balberg, N. Binenhaum, C. H. Anderson, Phys. Rev. Lett. 1983, 51, 1605.

[83] K. Y. Yan, Q. Z. Xue, Q. B. Zheng, L. Z. Hao, Nanotechnology 2007, $18,255705$.

[84] W. Zhou, Y. H. Ooi, R. Russo, P. Papanek, D. E. Luzzi, J. E. Fischer, M. J. Bronikowski, P. A. Willis, R. E. Smalley, Chem. Phys. Lett. 2001, 350,6 .

[85] Z. Shi, Y. Lian, F. Liao, X. Zhou, Z. Gu, Y. Zhang, S. Iijima, Solid State Commun. 1999, 112, 35.

[86] A. G. Rinzler, J. Liu, H. Dai, P. Nikolaev, C. B. Huffman, F. J. Rodrígez-Macías, P. J. Boul, A. H. Lu, D. Heymann, D. T. Colbert, R. S. Lee, J. E. Fischer, A. M. Rao, P. C. Eklund, R. E. Smalley, Appl. Phys. A 1998, 67, 29.

[87] B. Kitiyanan, W. E. Alvarez, J. H. Harwell, D. E. Resasco, Chem. Phys. Lett. 2000, 317, 497.

[88] C.-M. Yang, K. Kaneko, M. Yudasaka, S. Iijima, Nano Lett. 2002, 2, 385.

[89] N. Grossiord, Ph. D. Thesis, Eindhoven University of Technology, Eindhoven 2007.

[90] A. J. Hart, A. H. Slocum, J. Phys. Chem. B 2006, 110, 8250.

[91] N. Grossiord, J. Loos, J. Meuldijk, O. Regev, H. E. Miltner, B. van Mele, C. E. Koning, Compos. Sci. Technol. 2007, 67, 778.

[92] N. Grossiord, P. van der Schoot, J. Meuldijk, C. E. Koning, Langmuir 2007, 23, 3646

[93] W. Posthumus, Ph. D. Thesis, Eindhoven University of Technology, Eindhoven 2004.

[94] S. M. Wentworth, Charact. Mater. 2003, 1, 401. 